\title{
CLASES, CIUDADANOS Y CLASES DE CIUDADANOS \\ El ciclo electoral del pos-socialismo (1986-94)
}

\author{
Juan Jesús González* \\ UNED
}

\section{SOBRE EL DECLIVE POLITICO DE LAS CLASES}

Pocos temas han suscitado tanta polémica en los últimos tiempos como el de la relación entre estructura de clase, comportamiento político y configuración del mapa electoral. Si repasamos la bibliografía al respecto, parece difícil extraer algún tipo de consenso más allá de la simple evidencia de que tal relación, caso de poder establecerse, se ha hecho extraordinariamente compleja. En efecto, nadie en su sano juicio estaría dispuesto a defender en la actualidad algún tipo de conexión lineal o mecánica entre una cosa y la otra. El problema, por tanto, es si cabe establecer algún tipo de conexión y, en tal caso, qué elementos o factores intervienen en ella y permiten explicar la formación de las preferencias políticas de los ciudadanos.

Aunque la polémica cuenta con antecedentes en la crítica funcionalista de las clases, ha cobrado especial interés con la aparición de los siguientes argumentos:

* Este artículo es resultado de una investigación patrocinada por el Centro de Investigaciones Sociológicas, al que agradezco los medios materiales y técnicos que ha puesto a mi disposición. Agradezco también a Salvador Parrado su colaboración en la presentación de los datos. 
- el impacto de la posindustrialización sobre la organización del trabajo y la proliferación de nuevos grupos de interés cada vez más renuentes a ser integrados en estrategias de carácter clasista;

- la conformación de actitudes electorales de carácter racional-instrumental y el consiguiente debilitamiento de los mecanismos tradicionales de identificación política basados en la solidaridad de clase;

- la emergencia de nuevas fuentes de identidad social y política, frecuentemente articuladas en torno a los nuevos movimientos sociales;

- el impacto de la sociedad de consumo y el aburguesamiento de la clase obrera;

- la propagación de valores de corte posmaterialista, etc.

Todos estos argumentos implican, en último término, alguna forma de desalineamiento político y electoral con respecto al momento de esplendor industrial de las sociedades modernas, tal como quedó reflejado en la conocida expresión de S. Lipset según la cual el escenario político surgido del pacto de posguerra no era sino la "expresión democrática de la lucha de clases» (Lipset, 1960). En fecha todavía reciente, este mismo autor no ha dudado en decretar la muerte política de las clases (Lipset et al., 1991 y 1993), en lo que constituye, a mi juicio, un ejemplo particularmente significativo de algunos de los malentendidos más habituales en esta polémica.

Un malentendido frecuente se deriva de la confusión entre: a) la pérdida de centralidad de la clase obrera en las sociedades posindustriales, y $b$ ) la pérdida de relevancia del análisis de clase. Porque si bien es cierto que el primero de estos supuestos está apoyado por la más diversa evidencia, admite, no obstante, dos interpretaciones: a) el ocaso de las clases y del conflicto clasista, en cuanto fenómenos propios de una época superada; b) la transformación de la dinámica clasista desde un modelo bipolar, dominado por la contradicción entre trabajo y capital, a otro multipolar, donde entran en juego no sólo las nuevas clases medias, sino, probablemente, otros grupos sociales.

La primera interpretación ha dado lugar a una especie de dualismo histórico, según el cual los actuales argumentos en favor del desalineamiento tratan de contraponer una clase obrera comunitarista y solidaria propia de algún paraíso perdido a la clase obrera fragmentada y atomizada de nuestros días. No sólo la evidencia histórica sugiere una realidad menos romántica, sino que el fenómeno clasista es actualmente demasiado complejo para quedar reducido a esta simplificación (Marshall et al., 1988). El reciente cambio de posición por parte de autores como Lipset constituye, a mi juicio, una curiosa variante de este sesgo dualista, tal como se puede comprobar, por ejemplo, cuando dicen:

«Puesto que la clase obrera ha sido tradicionalmente muy dependiente de partidos y sindicatos, el declive de los partidos es letal de cara a la articulación de una específica posición de clase obrera. Conclusión: menos política de clase» (1993: 301). 
Tal razonamiento va de la mano de una concepción de la nueva clase media un poco al modo como Hegel caracterizaba al estamento funcionarial en su filosofía del Estado: puesto que, según estos autores, no se trata de una clase al estilo de las clases tradicionales (por un lado, no dispone de mecanismos organizativos de carácter inclusivo-integrador, tales como sindicatos o patronales; por otro, es portadora de valores universales, no clasistas), la nueva clase se convierte en un elemento adicional de disolución del carácter clasista de la política (ib.: 310). Sólo alguna reminiscencia de corte hegeliano puede dar por buena esta pretensión de universalismo de la nueva clase media, pues, tal como ha argumentado J. Goldthorpe, el hecho de que ésta no tenga una posición preconcebida respecto del capitalismo per se, no quiere decir, ni mucho menos, que carezca de intereses particulares y de estrategias de clase propias (Goldthorpe, 1993).

Ante la réplica de autores neomarxistas (Hout et al., 1993), Lipset et al. han tratado de matizar su posición advirtiendo que «la clase social ha perdido capacidad de explicar procesos sociales y especialmente políticos. Pero está todavía viva» (Lipset et al., 1993). Con lo que el certificado de defunción parece afectar tan sólo a los supuestos analíticos tradicionales del marxismo, así como a la antigua capacidad de las viejas clases para diseñar y protagonizar el escenario de la representación política al modo como lo hicieron en el período de posguerra. En cualquier caso, entre el aferramiento marxista a supuestos de escasa vigencia y el refugio de autores como Lipset en el eclecticismo teórico (que termina dejando la clase al mismo nivel epistemológico de los factores adscriptivos, ecológicos o religiosos), el debate parece condenado a la esterilidad a menos que estemos dispuestos a replantearnos profundamente sus coordenadas (Caínzos, 1989 y 1994; González, 1994b).

Pues una cosa es, como digo, la pérdida de centralidad de la clase obrera en el nuevo escenario político de las sociedades posindustriales y otra bien distinta es la obsolescencia del análisis de clase, y si ésta se ha producido no es tanto por la magnitud de las transformaciones sociales ocurridas en las últimas décadas como por la incapacidad para dar cuenta de ellas, sobre todo de las tres siguientes:

a) La expansión de las nuevas clases medias y su impacto sobre la dinámica política de las sociedades mesocráticas.

b) El impacto del Estado de Bienestar sobre los procesos de estructuración de clase. Parece claro, en este punto, que el análisis de clase ha tenido menos dificultades en identificar el efecto de la lucha de clases sobre la construcción del Estado de Bienestar, en cuanto fórmula de pacto social y de compromiso interclasista, que en identificar el impacto de este último sobre la dinámica clasista y la emergencia de nuevas líneas de división y conflicto social.

c) La creciente mercantilización de la política y el consiguiente debilitamiento de los mecanismos tradicionales de identificación política basados en la clase. No se trata sólo, como ya adelanté, de la progresiva implantación de 
actitudes racional-instrumentales entre el electorado, sino que, por decirlo en términos económicos, la oferta política tiende a prevalecer sobre la demanda, lo que refuerza el margen de maniobra del sistema de partidos para configurar el mapa electoral.

No conviene, en efecto, ignorar la capacidad de los partidos para conformar la demanda política, pese al estrechamiento del margen de maniobra de los gobiernos nacionales a la hora de desarrollar sus estrategias económicas. Pues si bien es cierto que los gobiernos tropiezan con dificultades crecientes para orientar el rumbo de las economías nacionales en un contexto de mundialización, tampoco conviene olvidar que el Estado de Bienestar ha brindado a los partidos, y en particular a los socialdemócratas, un amplio marco de oportunidades para contener el impacto desigualitario del mercado y el efecto dualista de las fases depresivas del ciclo económico (Esping-Andersen, 1990; Kitschelt, 1993; Merkel, 1995).

Este artículo abunda en la idea de que la suerte política y electoral de la socialdemocracia viene dada, entre otras cosas, por su propia capacidad para construir y sostener coaliciones electorales mediante estrategias que combinen un aumento de la eficiencia económica con una adecuada implementación de mecanismos redistributivos ${ }^{1}$. Creo que la experiencia española de la última década proporciona una interesante referencia en este sentido, especialmente desde el momento en que la consolidación del sistema democrático dejó de ser motivo de preocupación para los españoles. Dejo fuera del análisis las elecciones de 1982 y los primeros años de gobierno socialista, por cuanto, vistas en perspectiva, es claro que la excepcionalidad de aquellas elecciones tuvo mucho que ver con los problemas de inestabilidad democrática del momento, coaligados con una profunda crisis económica. Cabe suponer, por tanto, que las consideraciones de interés general prevalecieron sobre cualquier otro factor, incluidos los intereses de clase, y que no es hasta la segunda mitad de los ochenta, una vez que la vida política y económica quedó normalizada con la integración de España en la Comunidad Europea, cuando la dinámica política y electoral permitió aflorar de nuevo los intereses de clase.

\section{EL CASO ESPAÑOL: EL RETORNO DE LAS CLASES}

Es bien sabido que el sistema de partidos que comienza a configurarse en 1982 no tenía unas bases nítidas de carácter socioestructural, por cuanto la posición preeminente del PSOE propiciaba estrategias de partido catch-all o, si se admite la traducción, de partido omnívoro. Pero aquella situación, resultado de una coyuntura histórica muy específica, ha llevado con frecuencia a dar por

1 El lector interesado en el debate acerca de la vigencia o declive de la socialdemocracia puede acudir a Merkel (1994 y 1995). 
supuesto que las líneas de demarcación electoral nunca volverían a ser de naturaleza clasista. Autores como R. Gunther y J. R. Montero han dado recientemente otra vuelta de tuerca sobre este argumento, al afirmar que «las elecciones de 1982 cristalizaron al electorado español en términos de factores socioestructurales (...) pero a lo largo de los once años siguientes las bases socioestructurales del apoyo a los partidos se erosionaron» (1994: 532), en lo que sería, a primera vista, un ejemplo de descongelamiento de las bases tradicionales del alineamiento partidista. Ahora bien, puesto que tal interpretación choca con la abrumadora evidencia que estos mismos autores presentan acerca de la impermeabilidad entre la izquierda y la derecha del espectro electoral, Gunther y Montero optan, finalmente, por atribuir esta última (que sería un factor clave en la aparente estabilidad de este período) a «criterios ideológicos relacionados con las percepciones espaciales izquierda-derecha [en cuanto] mecanismo sustitutivo de los anclajes partidistas cuando están ausentes los socioestructurales o cuando han perdido fuerza a lo largo del tiempo» (ibidem).

Son varios los problemas que surgen en relación con este tipo de argumentos, siendo el primero de carácter teórico. Como los propios autores reconocen, el significado preciso de la escala de izquierda-derecha no es claro, lo que hace arriesgada cualquier tentativa de considerarla «un determinante del comportamiento político partidista» (ib.: 494-495). Pues si aceptamos que el autoposicionamiento ideológico pase a formar parte del explanans, no es fácil comprender que la decisión electoral quede del lado del explanandum. ¿Por qué no hacer a la inversa y explicar el autoposicionamiento por el voto? ${ }^{2}$

El segundo problema es de orden metodológico, pues aunque Gunther y Montero aluden reiteradamente a la relevancia de la clase como indicador de factores socioestructurales, el lector encuentra dificultades para saber lo que los autores quieren decir con ello. Sea como "estatus de empleo (asalariado/autónomo)»(ib.: 493), sea como una combinación de "estatus ocupacional, ingresos y la dicotomía asalariado/autónomo» (ib.: 515), los autores parecen, en cualquier caso, prestar una escasa atención al debate reciente sobre las clases y a los ingentes esfuerzos realizados por la sociología por identificar los cleavages sociales, es decir, las líneas de división y los mecanismos de cierre propios de las sociedades contemporáneas ${ }^{3}$.

Por último, llama la atención que, en ningún momento de su extenso artículo, los autores tomen en consideración las variables que actúan del lado de la oferta política, y en particular las políticas gubernamentales, a la hora de

2 Piénsese, por ejemplo, en el voto de castigo contra un partido ideológicamente próximo. Es probable que tal decisión vaya acompañada por un cierto desplazamiento en la escala izquierda-derecha, con el fin de reducir la disonancia cognitiva a que una decisión de este tipo da lugar. En otras palabras, el autoposicionamiento ideológico es, entre otras cosas, una forma de racionalización de la decisión electoral.

${ }^{3}$ Sobre los aspectos teóricos de este debate, véase mi artículo «El debate postmarxista sobre las clases», Política y Sociedad, 11, 1992. Sobre los aspectos empíricos puede verse mi otro artículo publicado en este mismo número con el título «La construcción empírica de las clases». 
explicar la suerte de los partidos en los países que les sirven de referencia para su análisis del comportamiento electoral. Pues pudiera darse el caso de que, tras la estabilidad que los índices de volatilidad electoral parecen traslucir, hubiese un proceso constante de transferencias electorales en respuesta a las políticas gubernamentales, con lo que aquella estabilidad sería tan sólo aparente. Algo de esto parece desprenderse de la inversión del perfil del votante socialista, que pasó de ser un votante más bien urbano, joven e ilustrado, a principios de los ochenta, a otro más bien rural, viejo y de bajo nivel educativo, una década más tarde, de tal suerte que si bien el PSOE consiguió mantener un volumen parecido de votos entre 1982 y 1993, está claro que los votantes de 1993 ya no eran los mismos que al principio ${ }^{4}$.

¿Cabe concluir, como hacen Gunther y Montero, que los anclajes socioestructurales de los partidos han perdido capacidad explicativa? ¿Sería entonces España un caso más en el proceso de desalineamiento que señalan los defensores del declive político de las clases? Otros autores como Torcal y Chhibber (1995) han dado, a mi juicio, un convincente desmentido a tales supuestos, hasta el punto de que la evolución política y electoral de la última década sería más bien la contraria de la que sugieren Gunther y Montero. De hecho, las elecciones de 1986 habrían sido la última oportunidad del PSOE para ensayar una estrategia típica de partido omnívoro, con una campaña dominada por vagas promesas ligadas al proyecto de modernización en curso, tal como sugería el eslogan elegido para la ocasión: "Por buen camino». En cualquier caso, como apuntan Chhibber y Torcal, la economía y, en particular, los problemas redistributivos no estuvieron en el centro de la campaña (ib.: 20).

Desde esta perspectiva, el escenario electoral de 1989 fue otro bien distinto. Por lo pronto, la política de saneamiento económico de la primera legislatura socialista preparó a la economía española para beneficiarse de la integración europea y de la prosperidad internacional de aquellos años, lo que originó el llamado efecto de salida del túnel, merced al cual los diversos sectores sociales se aprestaron a maximizar su participación en los beneficios (Paramio, 1992). En este contexto, la huelga general de diciembre de 1988 y la presión sindical para que el gobierno saldara la llamada deuda social empujaron al PSOE hacia una operación redistributiva de gran alcance y de consecuencias difícilmente previsibles en aquel momento. No parece exagerado decir que, en 1989, el gobierno socialista había perdido la iniciativa política y electoral ${ }^{5}$.

Por otro lado, la refundación del Partido Popular brindó a los conservadores la oportunidad de reformular su programa electoral desplazando el énfasis

${ }^{4}$ En tal caso, altos índices de volatilidad y alto volumen de transferencias habrían sido perfectamente compatibles, por cuanto la volatilidad toma como referencia la proporción de voto obtenida por los partidos, pero no implica que los votantes de cada uno sean los mismos entre una elección y la siguiente.

5 Así parece corroborarlo Maravall: «... tras su segunda victoria electoral en 1986, la estrategia de los socialistas cambió gradualmente: cuando sus iniciativas políticas encontraron resistencia seria, estuvieron menos dispuestos a seguir adelante» (1995: 243). 
desde cuestiones de indudable resonancia moral y religiosa (aborto, retirada de la LODE...) hacia las cuestiones económicas y fiscales que se habían convertido en la principal preocupación de las nuevas clases medias urbanas, tratando así de ganarse el apoyo de sectores procedentes de UCD que habían sido reticentes con Alianza Popular.

A resultas de todo ello, «en 1989 ambos partidos presentaron dos programas que no sólo diferían de los presentados con anterioridad, sino que hacían de los temas económico, fiscal y redistributivo el centro fundamental sobre el que giraba el debate político» (Torcal y Chhibber, 1995: 21).

Sirvan estas consideraciones para poner en cuestión algunos de los tópicos más frecuentes del análisis electoral y dejar claro, por lo pronto, que los alineamientos de corte clasista no están necesariamente reñidos con nuestra experiencia política más reciente, sino que su mayor o menor protagonismo se deriva de la específica correlación de fuerzas de cada momento histórico. Otra cosa es que la sociedad posindustrial modifique la naturaleza y el alcance del fenómeno clasista, y que, en lógica consecuencia, los partidos socialdemócratas tengan que amoldar sus estrategias a las exigencias propias de cada contexto.

El caso español es, a mi juicio, un buen ejemplo de esto en un doble sentido: a) en lo que tiene de ruptura con la experiencia socialdemócrata tradicional en materia de política económica (pues la mundialización de la economía hizo inviable cualquier tentativa de socialdemocracia en un solo pais); b) en lo que tiene de respuesta adaptativa ante las consecuencias no queridas o imprevistas de lo anterior. Puesto que lo primero se produce, básicamente, como consecuencia de la reducción del margen de maniobra de los gobiernos nacionales para influir sobre las variables económicas, los gobiernos socialdemócratas han tratado de compensar los costes sociales de políticas económicas cada vez más rigurosas mediante políticas de bienestar social.

Pero tampoco conviene sobreestimar la capacidad de los dirigentes a la hora de marcar el rumbo de los acontecimientos, cual deus ex machina en disposición permanente de integrar y reconducir las demandas del entorno, incluso cuando éstas entran en colisión con sus propios designios. Según un argumento bien conocido, las élites son decisivas a la hora de establecer la agenda política, «especialmente en los Estados-naciones que cuentan con unas sociedades civiles débiles caracterizadas por una marcada ausencia de organizaciones secundarias y de estructuras partidistas sólidas» (Torcal y Chhibber, 1995: 8). Este tipo de supuestos llevaron, en su día, a enfatizar en exceso el papel de los dirigentes políticos durante la transición, en tanto que una observación más distanciada ha tratado de subrayar no tanto su capacidad para marcar el como para aprender del rumbo de los hechos (Pérez-Díaz, 1993: 26 ss.).

En lo que aquí nos concierne, es dudoso que el deslizamiento estratégico del partido socialista, a la vista de los resultados de la huelga general de 1988, sea un buen ejemplo de «lo receptivos que pueden ser a ciertas presiones los partidos (catch-all)» (Torcal y Chhibber, 1995: 21). Pues o bien se trataba, en efecto, de mantener una estrategia catch-all, o bien se trataba, por el contrario, 
tal como señalan a renglón seguido estos mismos autores, de preservar el apoyo de aquellos «sectores sociales que le garantizan su posición predominante», en virtud precisamente de su "firme enraizamiento en un determinado cleavage» (ib.: 21-22).

Creo incluso que podemos llevar el argumento más allá, pues no se trataba sólo de que el PSOE perdiera con ello la posibilidad de conseguir una implantación significativa entre las nuevas clases medias, sino que las tensiones con los sindicatos amenazaban con erosionar la lealtad electoral de la clase obrera. La operación redistributiva tenía, entre otros objetivos, el de conjurar esta amenaza, pero hay indicios de que, por la forma en que se desenvolvió, generó efectos de sentido contrario. A la altura de 1988, era evidente que, pese al progresivo aumento de la competición política tanto por la derecha como por la izquierda del PSOE, la principal oposición al gobierno estaba fuera del Parlamento y era consecuencia más o menos directa de la ruptura en el seno de la familia socialista. Así las cosas, había dos maneras de plantear la operación redistributiva, ya fuera — como hacía el gobierno- tratando de asegurar el crecimiento, en cuanto condición sine qua non de la redistribución, lo que exigía mantener una cierta línea de reformas, y en concreto de reforma laboral; ya fuera, como querían los sindicatos, dando prioridad a la redistribución, aun cuando ello implicase restricciones al crecimiento, y en particular al crecimiento del empleo (Paramio, 1992).

Por las razones que discutiré más adelante, el diálogo se hizo imposible y, a la vista de los resultados del 14-D, los sindicatos optaron por desestimar cualquier oferta del gobierno, por sustancial que ésta fuera, de manera que cuando el gobierno terminó por atender las demandas sindicales ya era tarde para conseguir contrapartidas, pues los sindicatos se habían retirado de la mesa de negociaciones constituida a primeros de 1989. El impulso reformista acabó así cediendo a la presión social, con lo que la campaña del PSOE de octubre de 1989 se limitó a dar forma programática a la operación redistributiva culminada en el Decreto-ley de Medidas Adicionales de Carácter Social de marzo de ese mismo año.

Es claro que el papel de los dirigentes es crucial no sólo en el diseño de la oferta política, sino también en la configuración de la demanda... especialmente cuando llevan la iniciativa y consiguen integrar en su agenda política las reivindicaciones de los agentes sociales - pero no tanto cuando son éstos quienes imponen la agenda.

\section{CLASES Y CLASES DE CIUDADANOS}

Según una pauta más o menos consolidada en los países de nuestro entorno, los partidos socialdemócratas se enfrentan a la doble competencia de partidos liberal-conservadores, por un lado, y de partidos de nueva izquierda, calificada en ocasiones de libertaria o posmaterialista, por el otro. Frente al énfasis 
liberal en el mercado y en la eficiencia económica como principios sustantivos del orden social deseable, los socialdemócratas han defendido principios organizativos, generalmente de carácter público, tendentes a regular los efectos desigualitarios y, a menudo, imprevisibles del libre mercado. La fórmula de compromiso entre libertad e igualdad ha sido una cierta progresividad fiscal que, sin poner en peligro el crecimiento económico, permita la redistribución, con lo que la fiscalidad ha reemplazado, en la práctica política socialdemócrata, el principio clásico de fraternidad (Kitschelt, 1993 y 1994).

Frente a unos y otros, la nueva izquierda intenta desmarcarse del eje distributivo en que tradicionalmente han competido liberales y socialdemócratas, reclamando la solidaridad y la participación ciudadana ante la doble amenaza de las fuerzas del mercado y de la burocratización. De ahí que su espacio político dependa, entre otras cosas, de la medida en que prosperen prácticas que trasciendan los rituales democráticos propios de la vieja politica (Offe, 1988).

Dado el nivel de desarrollo social y político, la dinámica electoral de la última década en España ha sido todavía muy dependiente del eje distributivo (al que se refiere la oposición convencional entre izquierda y derecha), lo que ha permitido al PSOE concentrar casi toda su estrategia en uno de los flancos de la competición ${ }^{6}$. Con el fin de discutir los rasgos específicos de este proceso, comenzaré presentando mi estrategia de análisis, así como una hipótesis explicativa no sólo de las tendencias generales del proceso en su conjunto, sino, más concretamente, del vuelco electoral de 1994 en cuanto signo de agotamiento de dichas tendencias. Dedicaré este apartado a lo primero y abordaré lo segundo en el siguiente.

Tal como expuse con anterioridad (González, 1994a), parto de la distinción entre posiciones directas y posiciones mediadas de clase, y propongo considerar los grupos sociales beneficiarios de políticas de bienestar como un caso particular de estas últimas. Mientras las posiciones directas se definen por su participación laboral y, por ende, la percepción de salario directo, los segundos se caracterizan por la percepción de salario social o indirecto. Trato así de integrar al análisis de clase esos sectores que tradicionalmente han sido dependientes de la familia, pero que, merced a la expansión del Estado de Bienestar, han conseguido emanciparse mediante la percepción de una u otra forma de prestación o salario social.

El problema adquiere especial importancia debido a la creciente magnitud y presencia social de diversos colectivos que, por una u otra razón, quedan excluidos de la participación laboral. Fenómenos como la expansión del sistema educativo, el aumento de la esperanza de vida, las políticas de prejubilación, el aumento del paro estructural, no hacen, en último término, sino incrementar el protagonismo social de colectivos tales como la juventud, la tercera edad, los desempleados, etc. Importancia que cristaliza políticamente en la

${ }^{6}$ El lector puede encontrar un estudio comparado de las principales características de la competencia partidista en España en Kitschelt (1993 y 1994). 
medida en que estos colectivos se ven atribuidos de ciertos derechos sociales y de las políticas consiguientes.

Por lo general, las teorías de clase son perfectamente convencionales en lo que se refiere a este punto, pues, al tomar como referencia de su análisis el ámbito del mercado de trabajo y de la producción, tienden a adoptar el supuesto más o menos explícito de que cuando los individuos están excluidos de ese ámbito su vinculación familiar es la encargada de ligarles a la estructura de clase. A efectos de nuestra discusión, esto implica que dicha vinculación es el mejor predictor de su comportamiento electoral.

$\mathrm{Y}$, en efecto, así fue mientras la dependencia de estos colectivos era básicamente familiar, la familia era mucho más que un lugar de convivencia, y el cabeza de familia, o la persona principal del hogar, actuaba, por tanto, no sólo a título individual, sino de baluarte de las estrategias familiares. Pero ocurre que aquella dependencia se ha hecho en muchos casos pública (Garrido, 1993), con lo que la desfamiliarización de los comportamientos individuales ha llegado también a la política, como tendremos ocasión de comprobar más adelante - y no precisamente como consecuencia de conflictos generacionales al estilo de los años sesenta. Es aquí, según creo, donde cobra pleno sentido la idea de posición mediada de clase, pues justamente de lo que se trata es de identificar la mediación que opera en cada caso y momento concretos.

De acuerdo con mi propuesta inicial, los colectivos en posición de dependencia podían ser considerados clases pasivas o dependientes desde el momento en que la percepción de alguna forma de salario social abre la posibilidad de que su comportamiento electoral esté influido, o mediado, por las políticas respectivas encargadas de atender sus demandas. Más concretamente, mi hipótesis era que, dado que la situación española está muy condicionada por una experiencia reciente de implantación y expansión de políticas de bienestar, el nivel de dependencia pública era un factor determinante del apoyo o rechazo al partido gobernante. Y, en efecto, datos de 1991 nos permitían corroborar que la pauta diferencial entre colectivos tan diversos como los jubilados, los parados y los jóvenes (entendiendo por tal aquellos en posición de dependencia: estudiantes y buscadores de primer empleo) podía explicarse de esa manera (González, 1994a).

Mi propuesta hacía, no obstante, una salvedad con el colectivo de las amas de casa, el cual, dado el carácter eminentemente privado de su relación de dependencia, quedaba considerado como posición mediada por vía familiar, con lo que el mejor predictor de su comportamiento electoral era la posición de clase del cónyuge. Creo ahora, en cambio, que hay dos tipos de razones para reconsiderar aquella salvedad: la primera es teórica y obedece al hecho de que aquel razonamiento tendía a identificar salario social y prestación social, en lugar de tomar este último como un caso particular del primero. En otras palabras, la prestación social suele tener un carácter subsidiario por cuanto implica, en muchos casos, alguna forma de salario diferido que remite a cotizaciones sociales satisfechas con anterioridad. Pero no parece razonable suponer, 
por ejemplo, que el apoyo prestado por la tercera edad al PSOE en los últimos tiempos responde tan sólo a la política de pensiones y en modo alguno a la mejora de la cobertura sanitaria, como tampoco lo parece que las amas de casa sean insensibles a la política sanitaria o escolar.

La segunda razón es de orden empírico y viene dada por la evidencia reunida en los últimos tiempos de que, una vez asignada la clase del marido, las amas de casa emparejadas con trabajadores manuales parecen encontrarse en una situación de relativo divorcio político respecto a sus cónyuges, pues mientras una parte de éstos se ha radicalizado en favor de Izquierda Unida o ha optado por la abstención, las primeras parecen haberse mantenido más leales al PSOE (González, 19957). La idea de posición mediada de clase debe ser entendida, por tanto, como posición sometida a una doble influencia: en este caso, la posición de clase del cónyuge y la propia posición en cuanto clase pasiva.

El telón de fondo de mi razonamiento es que los alineamientos electorales obedecen cada vez menos al impulso de las políticas económicas que afectan al ámbito de la producción, y cada vez más a las políticas sociales que regulan la reproducción. En otras palabras, los conflictos distributivos característicos del viejo orden industrial van cediendo al empuje de las tensiones redistributivas derivadas de la financiación del Estado de Bienestar. Puesto que la esfera de la producción ocupa a una proporción cada vez menor del electorado, esto amplía, en principio, el margen de maniobra de los partidos políticos a la hora de buscar nichos electorales.

Conviene, en este punto, abandonar cualquier prejuicio de inspiración marshalliana acerca de la ciudadanía como principio de igualación social y de neutralización de los conflictos de clase, según criterios de universalidad (Marshall [1950], 1992). Pues si bien los derechos de ciudadanía proporcionan un ámbito para la conformación de comunidades de intereses no clasistas, sus resultados en términos de desigualdad pueden ser muy diversos, incluyendo la reproducción de las desigualdades de clase, amén de la generación de nuevas formas de desigualdad.

Nos encontramos así, por el lado de la demanda, con colectivos dependientes más o menos organizados que compiten por el reconocimiento de sus respectivos derechos sociales, a la conquista de recursos públicos que reduzcan su sentimiento de privación relativa. Mientras que, por el lado de la oferta, los partidos políticos establecen prioridades mediante fórmulas de equilibrio entre la equidad social y el rendimiento electoral de las diversas políticas. Es evidente, por ejemplo, que la rentabilidad no es la misma cuando se trata de políticas de salario diferido (dejando al margen su efecto redistributivo), tal como ocurre con las prestaciones sociales de carácter subsidiario (pensiones contributivas, subsidio de desempleo, etc.), que cuando se trata de políticas de salario

Queda por saber en qué medida este divorcio implica una individualización del voto, tal como he sugerido con anterioridad, o, por el contrario, responde a una decisión estratégica, más o menos consciente, de reparto de apoyos entre las dos opciones de izquierda, ante una situación de crisis de la izquierda. Espero poder abordar este asunto en otra ocasión. 
social bajo principios de universalidad, como la sanidad o la enseñanza. Como no es la misma tampoco entre las políticas sanitarias y las educativas.

Pues mientras las políticas de salario diferido afectan directamente al bienestar de sus perceptores (los cuales tenderán a retribuir electoralmente al partido encargado de su implantación), las políticas educativas no lo hacen, en el mejor de los casos, más que indirectamente, pudiendo decirse que su efecto directo no es otro que la elaboración de expectativas profesionales y de inserción laboral. La educación es, por definición, una inversión, tanto por el lado de la oferta como de la demanda, cuya rentabilidad depende del ciclo económico, de suerte que cuando el ciclo económico permite el cumplimiento de expectativas, la inversión será rentable para ambas partes, sea en términos de bienestar o de retribución electoral. No así cuando el ciclo se invierte, con la consiguiente frustración de expectativas.

Estos son, según mi hipótesis, algunos de los principios que rigen la economía electoral de las políticas de bienestar en fase de implantación y universalización, tal como ha ocurrido en España en los últimos diez o quince años. No hay que decir, por tanto, que pierden sentido una vez que tales políticas están implantadas y son percibidas por la ciudadanía como derechos adquiridos que se dan por supuestos.

\section{EL POS-SOCIALISMO: ¿UN SOCIALISMO SIN SINDICATOS?}

Como es bien sabido, la experiencia de gobierno de los partidos socialistas mediterráneos ha sido bien diferente de la que había tenido la socialdemocracia en el centro y norte de Europa, tanto por razones geopolíticas como por la diferente época en que a unos y otros les tocó gobernar (Merkel, 1992 y 1995). Esta ruptura con la tradición socialdemócrata se hizo particularmente visible tras el fracaso temprano del primer gobierno socialista francés. Con este precedente, el PSOE asumió las tareas de gobierno con la clara convicción de que la anterior experiencia socialdemócrata había dejado de ser una referencia obligada, especialmente en lo que afectaba a las consabidas recetas keynesianas en materia de política económica (Pérez Royo, 1992; Maravall, 1995).

Este giro pos-socialista ha tenido implicaciones cruciales en el diseño de la acción de gobierno: por lo pronto, objetivos clásicos como el pleno empleo dejaron de ser prioritarios en un contexto de políticas de ajuste más o menos duro. En consecuencia, las organizaciones sindicales perdieron el papel privilegiado de participación y corresponsabilidad que las políticas keynesianas les habían asignado, con lo que el modelo socialdemócrata tradicional de vinculación entre partido y sindicato entraba en crisis - lo que devino, con el tiempo, ruptura de la familia socialista española.

Cabía pensar que este nuevo escenario dejaba abierta la posibilidad de que el PSOE se convirtiese en un partido interclasista, con una notoria implantación entre ciertos segmentos de las nuevas clases medias. Sin embargo, analis- 
tas como Joaquín Leguina habían advertido ya en las elecciones generales de 1986 un movimiento de sentido contrario según el cual «el PSOE pierde apoyo en las capas medias activas de forma significativa, pérdida que se compensa, en buena parte, con el nuevo voto de capas agrarias y categorías económicamente dependientes, tradicionalmente votantes de la derecha» (1986: 124). En el origen de estos primeros corrimientos se encontraba, según este mismo autor, la política de rentas, y más en concreto: "la fiscalidad (impuesto sobre la renta), mucho más eficaz sobre las capas medias asalariadas que sobre cualquier otra; la seguridad social (subsidio de desempleo, pensiones...), relativamente beligerante a favor "del campo" (receptores) frente a "la ciudad" (pagadores); la política de función pública (congelación salarial, ley de incompatibilidades)...»(ib.: 118).

Pese a que "el bloque social de progreso" sobre el que pretendía asentarse el proyecto modernizador del PSOE se viese "resentido" por tales corrimientos, J. Leguina concluía que "la extensión geográfica del voto socialista ha ganado con ello" (ib.). Conclusión corroborada por Feldman et al. en su análisis de esas mismas elecciones, coincidente en subrayar la diversificación social de los apoyos obtenidos por el PSOE, con lo que «el futuro de las actuales bases de la estabilidad política en España reside en las acciones del PSOE», quedando así en sus propias manos la posibilidad de «mantenerlas o perderlas» (1989: 63).

Como veremos más adelante, los corrimientos electorales detectados por J. Leguina en 1986 fueron sólo el principio de cambios más drásticos en el perfil electoral del PSOE, según los cuales su centro de gravedad sufrió, primero, un proceso de proletarización al final de los años ochenta y, más tarde, se desplazó hacia las clases pasivas de jubilados y amas de casa. ¿Cómo explicar este doble desplazamiento en virtud del cual el partido que se presentó en 1982 como adalid de la modernización, y ha tratado de conducir la economía bajo criterios de eficiencia, se apoya diez años más tarde sobre las capas más dependientes de la población?

No hay que decir que en la genealogía de este proceso intervienen demasiadas cosas, así que sólo voy a mencionar tres de ellas en el orden cronológico en que, según creo, se han sucedido. La primera tiene que ver, como apuntaba Leguina, con el fuerte aumento de la presión fiscal durante los años ochenta, que junto con el boom económico hizo posible la operación redistributiva de marras: me refiero a la retirada de apoyo al PSOE por parte de ciertos sectores de las nuevas clases medias, retirada que se inicia hacia mediados de los años ochenta. La segunda ha tenido una génesis muy compleja y es probablemente la que afecta más de cerca a la conclusión de Feldman et al. que hacía reposar la estabilidad política en la propia estrategia del PSOE: me refiero a la confrontación o desavenencia entre gobierno y sindicatos, huelga general incluida (Juliá, 1988), con la consiguiente inversión del apoyo relativo procedente de los obreros más cualificados, estables y organizados respecto a los menos. La tercera se refiere a la disolución del apoyo recibido de estos últimos como consecuencia del efecto combinado - socialmente explosivo- de recesión, 
desempleo, reforma laboral y caída de la cobertura de desempleo, tal como se ha producido en los últimos años.

En cuanto a lo primero, no pretendo, ni mucho menos, decir que el aumento de la presión fiscal durante los años ochenta explique por sí solo la retirada de estas clases medias del ámbito electoral del PSOE, por cuanto la cadena causal entre una cosa y la otra se compone de numerosos eslabones intermedios, uno de los cuales viene dado, a mi juicio, por el semifracaso de las sucesivas tentativas de reforma de la administración y de algunos servicios públicos. Pero sí quiero, al menos, sugerir un principio de explicación que debería ser objeto de discusión más detallada en otra ocasión.

De manera sumaria, defiendo la idea, dentro de mi argumento general sobre la implantación del Estado de Bienestar, de que la orientación políticoelectoral de las clases medias es función, entre otras cosas, de un cálculo estratégico que tiene en cuenta, de un lado, el coste de la presión fiscal y, de otro, su impacto sobre la expansión de ciertos sectores como la sanidad y la educación que constituyen nichos laborales preferentes de ciertos grupos profesionales y técnicos. El resultado de este cálculo es, inevitablemente, la escisión de las clases medias entre aquellos segmentos más dependientes del sector privado y, por tanto, más renuentes a la presión fiscal, y los más dependientes del Estado y, por tanto, de una estrategia de expansión de los servicios públicos. Es lo que algunos autores americanos han denominado el welfare split (Herring, 1989).

El segundo factor se deriva de la dinámica de confrontación que ha marcado las relaciones entre gobierno y sindicatos durante la última década y que, como ya apunté, se manifestó, hacia finales de los ochenta, en una inversión del apoyo recibido por el PSOE de los obreros cualificados en comparación con los no cualificados. Como es bien sabido, la influencia de los sindicatos es mayor entre los primeros (Taboadela, 1993), por lo que la confrontación supuso que el gobierno recibiera cada vez menos apoyo de éstos y más de los segundos, en términos relativos. De ahí que mientras, en la primera mitad de los ochenta, el grueso de los trabajadores situados en el área de influencia de los sindicatos de clase votaba al PSOE, la dinámica de conflicto entre gobierno y sindicatos conllevó un desplazamiento de sus preferencias electorales en favor de Izquierda Unida.

Este desplazamiento ha persistido en los últimos años con la polémica sobre la reforma laboral, alimentando el crecimiento electoral de IU. De ahí la ansiedad con que los dirigentes del PCE siguen los pasos de los sindicatos, y en particular de CC.OO. La razón es doble: por un lado, el balance electoral de IU depende vitalmente del apoyo de los trabajadores situados en el área de influencia de CC.OO; por otro, la crisis de UGT ha devuelto a CC.OO. la hegemonía que perdió en los años ochenta ${ }^{8}$.

${ }^{8}$ Según la Encuesta de Estructura y Conciencia de Clase de 1991, UGT y CC.OO. se encontraban en una relación de paridad tanto en lo que se refiere a afiliación como a simpatía. Según el estudio 2088 del CIS, en 1994 había una relación favorable a CC.OO. de 1,2 a 1, en lo 
No es nada fácil resumir la genealogía de la confrontación entre gobierno y sindicatos, pero sí podemos recordar alguno de sus aspectos cruciales, y en particular, la política laboral. Para ello hay que tener en cuenta el cambio de escenario registrado a mitad de los años ochenta en la relación entre gobierno y sindicatos. Hasta ese momento, el escenario de la transición y posterior consolidación democrática estuvo caracterizado por un juego de cuatro actores (gobierno, patronal, UGT y CC.OO.) sujeto a dos reglas fundamentales: a) por un lado, se trataba de un juego no pautado que podía ser bipartito o tripartito según la coyuntura política y el grado de competencia entre ambos sindicatos; $b$ ) por otro, implicaba mayor o menor grado de colaboración entre el gobierno y, cuando menos, el sindicato socialista, antes incluso de que el gobierno fuese de este signo, cooperación inserta en una estrategia que podíamos designar pro-neocorporativa, intentando secundar el modelo socialdemócrata europeo de posguerra.

Aunque no pueda decirse que esta experiencia fuera de alto rendimiento en términos económicos, más allá de sus innegables efectos de moderación salarial, tampoco cabe duda alguna respecto a su notable eficacia en términos sociopolíticos y organizativos, especialmente en lo que hace al mutuo reconocimiento y legitimación de las partes en el proceso de constitución e institucionalización de actores sociales y políticos, gobierno incluido (Pérez-Díaz, 1993). Para los sindicatos de clase este proceso parecía sentar las bases de una dinámica neocorporativa en la que, una vez alcanzada una situación de duopolio de representación de los trabajadores, su capacidad de influir sobre las políticas sociales y económicas era incuestionable? . El problema es que, tras la llegada del PSOE al gobierno, esta expectativa, en lugar de consumarse, se frustró.

Es aquí donde entra en juego el giro pos-socialista al que hacía referencia al principio de este apartado, de tal suerte que cuando los sindicatos, y en particular UGT, dieron por resueltos los tres problemas sobre los que había pivotado su estrategia hasta entonces (la crisis económica, la consolidación democrática y la construcción del nuevo marco de relaciones laborales), y creyeron, por tanto, llegado el momento de cambiar los términos de la negociación con el gobierno, no consiguieron acordar los nuevos términos. Cabía, en principio, una doble posibilidad, según que se pusiera el énfasis en politics o en policies.

En el primer caso, los sindicatos podían exigir mayor presencia institucional y más capacidad de intermediación a cambio de mantener una cierta aquiescencia respecto de la política del gobierno. El problema es que esto requería, cuando menos, dos condiciones: de un lado, sindicatos efectivamente

referente a afiliación, y de 1,7 a 1 , en lo que hace a simpatía. En conjunto, lo que podemos denominar el área de influencia (afiliación más simpatía) de CC.OO. era, en esta última fecha, en torno a un 50 por 100 mayor que la de UGT.

9 Sobre el carácter pro o semi-corporativo de la relación entre gobierno y sindicatos hay una amplísima bibliografía que desborda el ámbito de este artículo y a la que no hago, por tanto, referencia. 
decididos a corresponsabilizarse del cumplimiento de los eventuales acuerdos; de otro, un gobierno realmente dispuesto a la transacción.

Hay diversos indicios de que estas condiciones no se daban, o al menos no en la dosis suficiente: en el caso de UGT, porque los acuerdos obtenidos en la línea del AES de 1985 dejaban entre sus bases potenciales una secuela de excesiva complicidad en el seno de la familia socialista (Maravall, 1995: 221 ss.); en el caso de CC.OO., porque cuanto más relevantes fueran los acuerdos obtenidos, más evidente resultaba la debilidad política de Izquierda Unida: en otras palabras, podía parecer que el gobierno negociaba con los sindicatos lo que, dada la ausencia de oposición política propiamente dicha, era superfluo negociar en el Parlamento. En ambos casos, porque las experiencias anteriores de negociación invitaban a la cautela sobre la propia capacidad organizativa para asegurar el adecuado cumplimiento de los acuerdos.

Por el lado del gobierno, era no menos evidente que la hegemonía electoral de los años ochenta animó, primero, a los responsables de la política económica y, más tarde, a amplios sectores del partido a actuar libres de las servidumbres propias de la tradicional relación entre partido y sindicato. Según el citado autor, «en las estrategias gubernamentales fueron ganando terreno el "decisionismo" y el "mandatismo" frente a un neocorporativismo muchas veces considerado lento e ineficiente en términos económicos" (ib.: 220), y aunque Maravall se refiere al conjunto de los países avanzados, el caso español no se escapa del diagnóstico.

Pero cabía también la posibilidad de poner el énfasis en las policies, y concretamente en la política laboral, con el fin de obtener los mejores resultados posibles en términos de crecimiento económico y creación de empleo. Esto requería, a su vez, dos condiciones: por un lado, que los sindicatos comprendiesen la verdadera naturaleza de la crisis y abandonasen su creencia nä̈ve en recetas keynesianas pasadas de fecha; por otro, que los trabajadores más organizados accediesen a moderar sus exigencias salariales y, sobre todo, de seguridad laboral, aun cuando fuesen percibidas como justas recompensas por los sacrificios realizados durante el período anterior.

El problema adicional, en este caso, es que hacía falta también un gobierno no sólo con mayoría parlamentaria, sino con autoridad moral suficiente para regular el efecto de salida del túnel, en el momento de la recuperación económica, y evitar así que diversos sectores sociales intentasen imponer sus particulares intereses o su capacidad de veto frente a los demás. Si a ello añadimos errores de apreciación por parte del propio gobierno sobre los problemas que, a la altura de 1988, afectaban al mercado de trabajo, no cuesta mucho comprender que se perdiera aquella extraordinaria oportunidad de avanzar en la resolución de los problemas que con carácter endémico aquejan al empleo en España.

Pues, como apunta Luis Garrido, sólo la «falta de conciencia» respecto de la mejora en curso del proceso de inserción laboral de los jóvenes como efecto combinado de la expansión económica y las nuevas formas de contratación 
introducidas en 1984 (Garrido, 1995: 32) puede explicar el empeño del gobierno en la propuesta de un Plan de Empleo Juvenil cuya principal virtud no estaba tanto en facilitar un desbloqueo laboral que ya se estaba produciendo como en concitar la confrontación sindical y servir, como se recordará, de detonante de la huelga general del 14-D-88. Aquellas medidas de 1984 implicaron una considerable flexibilización de la entrada en el mercado de trabajo, pero, más allá de sus efectos saludables, habían comenzado a mostrar también sus efectos perversos de segmentación, dando pie al conocido discurso sindical sobre la precarización.

Típicamente, la segmentación es resultado del efecto combinado de la reducción de costes de entrada en el mercado de trabajo junto con el mantenimiento de altos costes de salida. Así, cuando las empresas encuentran dificultades para ajustar sus plantillas por el lado del despido, tienden a hacer abuso de las medidas de flexibilización de la entrada, y en particular de la contratación temporal, provocando una alta rotación entre el paro y la ocupación. Esto afecta, sobre todo, a las diversas categorías de trabajadores manuales, progresivamente divididas entre lo que se ha dado en llamar insiders y outsiders, según que se encuentren protegidos o desprotegidos en materia laboral (EspingAndersen, $1993 b$ y $1993 c)^{10}$.

En términos de política laboral, esta dinámica de segmentación aboca a un dilema, pues o bien se rebajan las condiciones de ciertos sectores insiders, al tiempo que se reduce el grado de exclusión de los outsiders, o se corre el riesgo de que estos últimos se consoliden como tales dando lugar a la formación de infraclases, es decir, de colectivos condenados a la inestabilidad laboral y cada vez más dependientes de políticas asistenciales. En países como España o Italia, este dilema tiene una importante dimensión generacional, por cuanto los insiders suelen ser trabajadores adultos, en tanto que los outsiders suelen ser jóvenes, de tal suerte que su eventual resolución depende de las estrategias familiares (Esping-Andersen, 1995). Cuando éstas optan, como es de esperar, por una defensa a ultranza de la posición del cabeza de familia, los sindicatos encuentran el terreno abonado para una estrategia de resistencia férrea ante cualquier tentativa de flexibilizar la salida de los insiders, por cuanto las familias prefieren asegurar la situación de los cabezas que aumentar la probabilidad de inserción laboral de los jóvenes.

Si tenemos en cuenta, por último, que la implantación preferente de los sindicatos está muy localizada no sólo entre los insiders, sino, más concretamente, en el sector público (Taboadela, 1993), donde la protección laboral significa, en ocasiones, una suerte de blindaje, es claro que ningún gobierno

${ }_{10}$ A efectos del modelo de clase que vamos a utilizar aquí, serán identificadas por su nivel de cualificación, según que se trate de trabajadores manuales cualificados o no cualificados. Aunque cualificación no es sinónimo de protección laboral, hay una correlación lógica entre una cosa y la otra en la medida en que la cualificación tiene que ver con la antigüedad en el puesto y, por ende, con la estabilidad. 
cuenta con margen de maniobra suficiente para el arbitraje en materia de relaciones laborales o industriales, por cuanto no puede escapar, en último término, a su condición de principal patrón de los sindicatos.

Creo que estas consideraciones ayudan a entender la huelga general de finales de 1988 y lo ocurrido después entre gobierno y sindicatos. Pero no es fácil identificar el punto de equilibrio a la hora de encontrar responsabilidades: es evidente, por un lado, que el gobierno de aquel entonces no estaba siendo coherente con los compromisos adquiridos en el XXXII Congreso del PSOE (1987) en lo tocante a modificar los criterios del gasto público, recomponer el diálogo social y recuperar la autoridad moral ${ }^{11}$. Con estas premisas, cualquier tentativa de diálogo hubiera sido más verosímil si el reconocimiento de la "deuda social» se hubiera hecho antes y no después de la huelga, y si se hubieran atajado las primeras manifestaciones de enriquecimiento ilícito, corrupción y clientelismo.

Por el otro lado, los sindicatos encontraron una coyuntura adecuada para reforzar su específica identidad sindical mediante la unidad de acción y la reactivación de un rasgo que, pese a haber estado latente durante la transición, parece profundamente arraigado en la cultura sindical española. Pues, como ha argumentado Santos Juliá (1988), uno de los subproductos históricos de largas y reiteradas experiencias de gobiernos ilegítimos y partidos débiles ha sido la creencia, más o menos explícita, de que los sindicatos constituyen la garantía última de defensa de los trabajadores, así como los depositarios finales de la legitimidad frente a oscuras alianzas de la patronal, los partidos y el gobierno de turno, siempre dispuestos a servirse de la política para intereses espurios. En una coyuntura de devaluación político-ideológica del partido gobernante y de ausencia de una verdadera oposición política, este resabio antipolítico puede reactivarse, empujando a los sindicatos a asumir un papel que, en principio, no es el suyo.

Como escribiera el citado Juliá: «El problema radica en si con esa cultura sindical es posible hoy ir a alguna parte» (1988: 105). Pasados los años, quizá lo único de lo que podemos estar seguros es de que se ha ido a varias huelgas generales... y a una crisis irreversible en el modelo de relación entre partidos y sindicatos. Y si bien está claro que el modelo tradicional pasó a la historia, no lo está tanto en qué puede consistir el nuevo modelo.

\section{EL VUELCO ELECTORAL DE 1994}

Llegamos así al tercero de los factores que han forzado el desplazamiento del centro de gravedad del electorado socialista durante la última década. Según mi argumento, el PSOE sufrió, primero, un proceso de proletarización

11 Véase el editorial de El País de 13 de diciembre de 1988, en Juliá (1988: 225 ss.). 
al final de los años ochenta y, más tarde, se desplazó hacia las clases pasivas de jubilados y amas de casa. Una vez expuesta, a grandes rasgos, la genealogía del conflicto entre gobierno y sindicatos, en cuanto variable crucial de la mencionada proletarización y, más concretamente, del desplazamiento del apoyo al PSOE desde los trabajadores manuales más cualificados, estables y organizados (insiders) a los outsiders, la cuestión ahora es averiguar las razones del segundo desplazamiento y, en particular, de la pérdida del apoyo de estos últimos.

La cuestión es tanto más relevante por cuanto, en primer lugar, este segundo desplazamiento culmina la consabida inversión del perfil electoral socialista, que pasó de ser un perfil más bien urbano, joven e ilustrado, a principios de los ochenta, a otro más rural, notablemente envejecido y de bajo nivel educativo, una década más tarde. De tal suerte que si bien el PSOE consiguió mantener un volumen parecido de votos entre 1982 y 1993, está claro que los votantes de 1993 ya no eran los mismos que al principio.

En segundo lugar, porque afecta a la hipótesis ya mencionada de Feldman et al. según la cual la diversificación de los apoyos sociales del PSOE constituía la mejor garantía de estabilidad política. Ya he expuesto en otra ocasión (1994a) que, a la altura de 1991, los apoyos electorales del partido socialista estaban, por contraste, muy concentrados entre las capas sociales más bajas, lo que implicaba, en términos empresariales, una alta concentración de riesgo. Pues, por tratarse de sectores muy vulnerables, cualquier cambio en la situación económica y/o cualquier inadecuación en las políticas encargadas de atender estos sectores podía acarrear graves consecuencias electorales, tal como ocurrió en las elecciones europeas de 1994.

Aquella inversión del perfil electoral obedece, entre otras cosas, a la operación redistributiva de la segunda mitad de los ochenta y al impacto diferencial de las políticas sociales y de bienestar desarrolladas durante la última década, dada la prioridad concedida a capítulos tales como las pensiones y la cobertura sanitaria, seguidos de la cobertura de paro. Prioridades que han prevalecido al mismo tiempo que amplios segmentos de jóvenes y mujeres permanecían al margen no sólo de una posible inserción laboral, sino también de la percepción de alguna forma de salario social ${ }^{12}$.

Esto es particularmente visible en el caso de los jóvenes, para quienes la expansión del sistema educativo (principal forma de salario social en su caso), por importante que haya sido, ha compensado muy escasamente tanto las dificultades, a veces insalvables, de inserción laboral como de acceso a la vivienda.

12 Pues así como las mencionadas prioridades tienen mucho que ver con la satisfacción de la llamada deuda social, la exclusión laboral de jóvenes y mujeres tiene que ver con los problemas del mercado de trabajo y, en concreto, con las limitaciones de la reforma laboral emprendida a mediados de los años ochenta. Pero la dinámica de confrontación entre sindicatos y gobierno y, en particular, el resultado de la huelga general de 1988 significó que, así como se atendió a lo primero, quedó por resolver lo segundo (González, 1994a). 
Según un estudio reciente, entre 1976 y 1994 «la edad de acceso al empleo se ha retrasado seis años, la del matrimonio tres años y el logro de la vivienda dos años» (Garrido y Requena, 1995 13).

Como tendremos ocasión de comprobar más adelante con datos de 1991, en esa fecha la coalición de nuevas y viejas clases medias sobre la que se asientan los partidos conservadores recibía ya importantes refuerzos del colectivo juvenil (tal como queda definido en el próximo apartado), en tanto que el partido socialista dependía en gran medida de una coalición entre jubilados y outsiders (tanto trabajadores no cualificados como parados), principales beneficiarios de las medidas redistributivas de 1989. Estos últimos venían apoyándose en las medidas laborales emprendidas a mediados de los ochenta para conseguir su inserción, una vez iniciada la recuperación económica. No obstante, lo que pudo ahorrarse en políticas pasivas de protección al desempleo, debido a la reducción de éste, acabó gastándose en políticas activas de fomento del empleo, debido al aumento de la contratación temporal incentivada, con lo que también aquí llegaron los efectos de la operación redistributiva (Garrido, 1995: 33).

El problema es que el apoyo de los outsiders al gobierno socialista dependía mucho del ciclo económico y, en concreto, de la medida en que el crecimiento permitía sostener altos niveles de gasto social, incluyendo una amplia cobertura de paro, lo que resulta inviable en fase de recesión, cuando el desempleo crece, la recaudación fiscal se reduce y el gasto se dispara.

Hay que tener en cuenta que este proceso es tanto más rápido cuanto que, por tratarse de empleo temporal, las empresas realizan un ajuste casi automático de sus plantillas. De hecho, en dos años se perdió un millón de empleos asalariados de los dos millones y medio que se habían creado en el quinquenio anterior (Garrido, 1995). Si, además, el gobierno emprende medidas de reforma laboral al tiempo que desciende la tasa de cobertura de desempleo ${ }^{14}$, el apoyo de los trabajadores más proletarizados y, por ende, de los parados (que vienen a ser lo mismo, debido a la rotación) se pierde irremisiblemente, no sólo por temor al despido, sino por temor también a la desprotección ${ }^{15}$.

La conclusión es obvia: la crisis, aunque sea incipiente y parcial, de algunas políticas de bienestar, como consecuencia de la incapacidad para hacer frente a la explosión del gasto social en una coyuntura recesiva, amenazaba la coalición

13 Todo lo cual lleva a estos autores a recomendar una política de vivienda que, «a la mayor brevedad», facilite la formación de nuevos hogares (Garrido y Requena, 1995). No parece, sin embargo, que los actuales rigores presupuestarios dejen mucho margen a este tipo de iniciativas.

14 Baste recordar que, así como la cobertura de desempleo se duplicó entre 1989 y 1993, pasando del 34 al 67 por 100, descendió nada menos que diez puntos en 1994 (Memoria del CES de 1994).

15 El País de 26 de junio de 1995 comentaba la aparición del informe anual del Banco de España con el siguiente titular: «La renta familiar descendió por primera vez en los diez últimos años, al caer un punto en 1994». A la hora de identificar las causas, el banco emisor destaca la moderación salarial y "la importante desaceleración en las prestaciones sociales», con referencia expresa a las reformas del sistema de protección por desempleo acometidas entre 1992 y 1994. 
electoral socialista de principios de los noventa. Esto explica, al menos en parte, lo que ocurrió en las elecciones europeas de 1994, cuando los sectores más proletarizados de los trabajadores optaron bien por la radicalización y el apoyo a IU, bien por la abstención. De tal suerte que, además del impacto que con carácter más o menos general hayan podido tener los escándalos de corrupción que protagonizaron la primavera de 1994, es preciso contabilizar el efecto específico de la retirada de los outsiders, como enseguida veremos.

Así las cosas, los apoyos preferentes del PSOE han terminado por desplazarse hacia las clases pasivas de jubilados y amas de casa (lo que alguna prensa ha designado como "cortafuegos electorales»" ${ }^{16}$ ), para quienes los efectos de la operación redistributiva son mucho menos coyunturales.

\section{METODOLOGIA Y PRESENTACION DE LOS DATOS}

El análisis del perfil del electorado socialista tiene especial interés por cuanto, en una situación de partido predominante (en términos de Sartori), como fue la del período 1982-93, el perfil electoral del partido gobernante constituye el mejor indicador de la magnitud y la naturaleza de los cleavages sociales y políticos. Podemos distinguir, desde esta perspectiva, tres momentos cruciales en la evolución electoral de la última década: a) en primer lugar, la situación de mediados de los años ochenta, cuando el partido socialista gozaba todavía de una hegemonía electoral incontestable y, por ende, de un amplio margen de maniobra política; $b$ ) en segundo lugar, la situación de principios de los noventa, resultante de, al menos, tres factores: el boom económico de finales de los ochenta, la contestación sindical y la operación redistributiva que hemos comentado con anterioridad —éste es el escenario justo antes de iniciarse el declive electoral del PSOE; y c) la primavera de 1994, efecto combinado, por un lado, de la recesión económica de 1993, agudizada por el impacto inmediato de las medidas de reforma laboral ${ }^{17}$, y, por otro, de los escándalos por corrupción, todo lo cual generó un extraordinario malestar social y político que propició el vuelco electoral de junio de 1994.

El perfil electoral viene dado por la distribución relativa del voto. Mientras la distribución absoluta del voto informa de la proporción del electorado que apoya cada una de las opciones electorales, la distribución relativa se refiere a la composición interna de cada una de estas opciones (Heath et al., 1991: 64 ss.).

${ }^{16}$ El País, 29 de abril de 1995, con el siguiente subtitular: "Aznar mima a las amas de casa y a los jubilados para no volver a estrellarse en las urnas con ellos».

${ }^{17}$ No se quiere decir con ello que las medidas de reforma laboral adoptadas por entonces agudizasen la recesión, sino tan sólo que su impacto en el corto plazo suele ser irremediablemente doloroso en términos sociales, al margen de lo saludable que puedan resultar en el medio y largo plazo. 
En nuestro caso, nos informa de la proporción en que cada una de las clases sociales está representada en el electorado de cada partido.

Presentaré los perfiles que se obtienen a partir de la intención de voto manifestada en 1988, 1991 y 1994, corregida por el recuerdo de voto de las elecciones de 1986, 1989 y 1993, respectivamente ${ }^{18}$. Para ello utilizaré como variable independiente el modelo de clase de J. Goldthorpe para clasificar a los ocupados $^{19}$. Los no ocupados se clasifican en: a) parados con empleo anterior; b) jubilados; c) amas de casa ${ }^{20}, y$ d) jóvenes (entendiendo por tales estudiantes y buscadores de primer empleo).

Con el fin de facilitar la visualización de los perfiles electorales, las categorías del modelo resultante aparecen en el siguiente orden:

- Viejas clases medias (incluyen las clases IVa, IVb y IVc de Goldthorpe): pequeños empleadores y autónomos no profesionales, así como agricultores, pescadores, etc.

- Nuevas clases medias (equivalen a la clase de servicio de Goldthorpe): profesionales, técnicos, directivos y supervisores no manuales.

- Trabajadores no manuales (clases III $a$ y III $b$ ): empleados no manuales de rutina en la administración y el comercio, así como trabajadores de servicios personales y de seguridad.

- Trabajadores manuales cualificados (clases V y VI): supervisores manuales y obreros cualificados.

- Trabajadores manuales no cualificados (clases VIIa y VIIb): agrarios y no agrarios.

- Parados.

- Jubilados.

- Amas de casa.

- Jóvenes.

- Resto: no clasificables.

Para delimitar los perfiles electorales me serviré de los residuos ajustados (que aparecen junto a los porcentajes horizontales en las tablas anexas), los cuales nos informan de la medida en que una determinada clase apoya, cuando son

${ }^{18}$ Las encuestas de 1988 y 1994 proceden, respectivamente, de los estudios 1737 y 2088 del CIS. La de 1991 es la encuesta de Estructura, Conciencia y Biografía de Clase (ECBC). Puesto que la muestra de esta última se refiere a individuos entre 20 y 69 años (Carabaña et al., 1993), éste es nuestro universo de referencia en los tres casos. El tamaño muestral es de 27.000 entrevistas (estudio 1737), 6.000 (estudio 2088) y 6.600 (encuesta ECBC).

19 Respecto a la justificación teórica y a la operacionalización empírica de este modelo, véasne, respectivamente, González (1992a y 1992b).

${ }^{20}$ Las amas de casa han sido clasificadas en su conjunto porque las encuestas de 1988 y 1994 no permiten asignarles la posición de clase del cónyuge. 
positivos, o rechaza, cuando son negativos, cada una de las opciones electorales. Hay que tener en cuenta, por tanto, que son indicadores relativos al peso que esa clase tiene en el electorado de un partido, por comparación con el que tiene en el conjunto del electorado, y no pueden ser interpretados en términos absolutos. A efectos de mi argumento general, lo más relevante de la información contenida en las tablas puede resumirse en los gráficos que dan cuenta de la evolución del perfil electoral del PSOE y, a modo de espejo, del Partido Popular.

Si nos atenemos a la periodización hecha al principio de este apartado, parece razonable suponer que el primer escenario de referencia se mantiene, grosso modo, hasta 1988 y presenta un perfil electoral socialista que llamaremos clásico por su coherencia con los presupuestos tradicionales del proyecto socialdemócrata: los principales apoyos se localizan entre los trabajadores manuales (Przeworski, 1988). Este primer perfil que designamos clásico es fácilmente identificable por cuanto su representación gráfica toma, de acuerdo con el modelo de clase elegido, un trazado en forma de campana. La razón es la siguiente: los partidos socialdemócratas suelen competir, por su derecha, con partidos liberal-conservadores que tienen su ámbito de implantación preferente en las viejas y las nuevas clases medias (localizadas en la parte izquierda del gráfico adjunto). En tanto que compiten, por otro lado, con partidos de nueva izquierda que suelen contar con las preferencias, entre otros sectores sociales, de los jóvenes (en el sentido preciso que aquí damos al término), según un proceso que, en nuestro caso, se inicia, muy probablemente, con el referéndum sobre la OTAN, y que resulta perfectamente visible en 1988 (véase la tabla correspondiente y la parte derecha del gráfico) ${ }^{21}$.

De acuerdo con estos datos, los apoyos preferentes del PSOE estuvieron localizados, al menos hasta principios de 1988 (fecha de realización de nuestra primera encuesta), entre los trabajadores manuales y los parados con empleo anterior -que proceden en su mayor parte de empleos manuales. Las clases pasivas de jubilados y amas de casa constituían todavía una zona neutra relativamente abierta a la contienda electoral.

El segundo escenario (tal como se desprende de la Encuesta de Estructura y Conciencia de Clase de 1991) presenta, al menos, dos cambios significativos con respecto al anterior: por un lado, los trabajadores manuales prestan grados muy diferentes de apoyo por razón de su cualificación y estabilidad laboral, de tal manera que mientras los más cualificados y más estables (y, por ende, más organizados: clase obrera en sentido estricto) han comenzado a retirar su apoyo — como eco de la contestación sindical_, los trabajadores más proletarizados

${ }^{21}$ Aunque la penetración inicial de esta nueva izquierda, mejor o peor representada por Izquierda Unida, está localizada claramente entre los jóvenes, su presencia no tardará en hacerse notar también entre las nuevas clases medias y los trabajadores de cuello blanco, como puede apreciarse en los datos de 1991 y 1994. Sobre la génesis de este proceso en países del entorno, véase Kitschelt (1994). 
parecen intensificar el suyo - en respuesta a esa combinación de bonanza económica y de protección social derivada de la operación redistributiva; por otro lado, la operación redistributiva y, en particular, las medidas relativas al sistema de pensiones comienzan a cosechar sus frutos entre los jubilados.

En cualquier caso, el rasgo más significativo de este perfil está todavía del lado de las clases activas y radica en esa especie de línea diagonal que atraviesa la parte izquierda del gráfico y que señala una polarización entre, por un lado, los sectores de nuevas clases medias que están soportando en mayor medida el impacto fiscal de la operación redistributiva y, por otro, los trabajadores que, aun desempeñando tareas poco cualificadas, podían beneficiarse de la expansión económica y del desbloqueo de la inserción laboral. Se trata, por tanto, de un típico escenario protagonizado por la tensión entre insiders y outsiders, tal como argumentamos con anterioridad, que queda perfectamente reflejado en el perfil electoral de 1991 .

El problema, como vimos, es que el apoyo de los outsiders al gobierno socialista dependía mucho del gasto en materia de política laboral, ya fuese vía políticas activas o pasivas de empleo, lo que se hizo inviable durante la fase recesiva del ciclo económico, con el resultado que podemos apreciar en el tercero de los momentos de referencia: si en 1991 la bóveda de la campana había tomado forma de cúspide, en 1994 aparece hundida, a consecuencia de la retirada de los outsiders. Es claro que, además del impacto de la corrupción, se produjo el impacto combinado de la recesión, el desempleo y la desprotección, impacto que, como era de esperar, ha sido mucho más selectivo y ha castigado, sobre todo, a los trabajadores más proletarizados.

Al término del proceso, el perfil de 1994, corroborado en las elecciones de 1995 (González, 1995), viene dado por el papel de las clases pasivas de jubilados y amas de casa como "cortafuegos electorales». 
Evolución del perfil del electorado socialista (1988-1994)

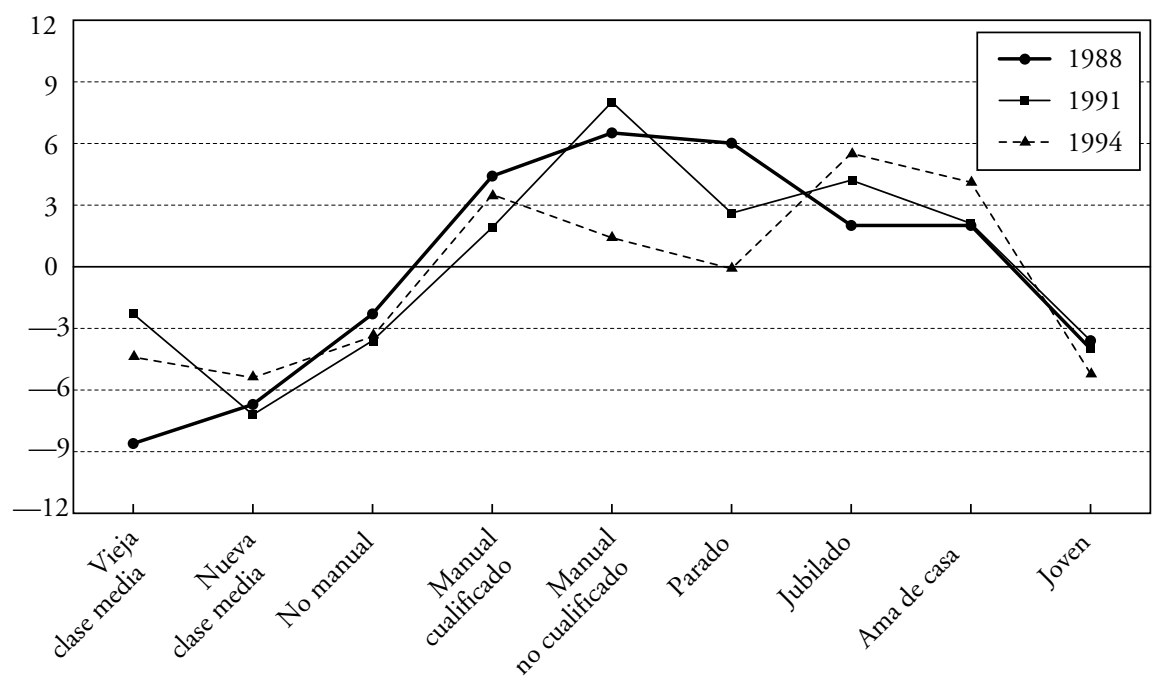

Evolución del perfil del electorado popular (1988-1994

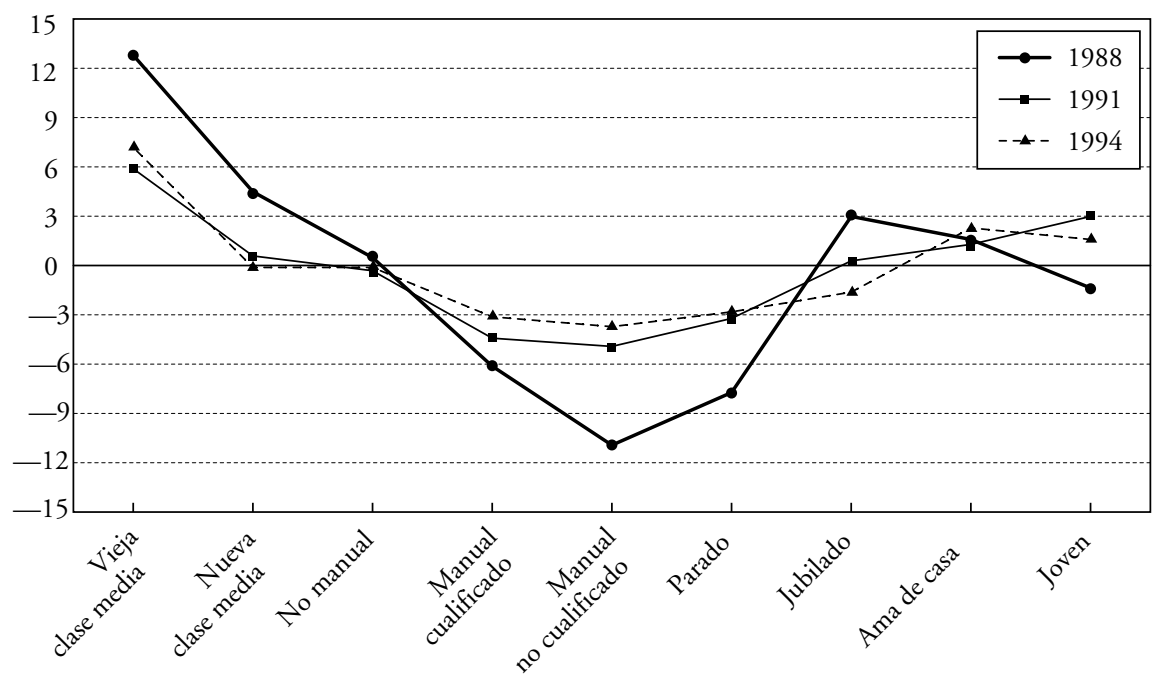


Intención de voto (válido) según clase (1988)

(Porcentajes horizontales/residuos ajustados)

\begin{tabular}{|c|c|c|c|c|c|c|c|c|c|c|c|}
\hline & \multicolumn{5}{|c|}{ Clases activas } & \multicolumn{6}{|c|}{ Clases pasivas } \\
\hline & $\begin{array}{l}\text { Vieja cl. } \\
\text { media }\end{array}$ & $\begin{array}{c}\text { Nueva cl. } \\
\text { media }\end{array}$ & $\begin{array}{c}\text { No } \\
\text { manual }\end{array}$ & $\begin{array}{l}\text { Man. } \\
\text { cual. }\end{array}$ & $\begin{array}{l}\text { Man. no } \\
\text { cual. }\end{array}$ & Parado & Jubilado & $\begin{array}{c}\text { Ama } \\
\text { de casa }\end{array}$ & Joven & Resto & Total \\
\hline PP & $\begin{array}{l}17,5 \% \\
12,8\end{array}$ & $\begin{array}{l}9,8 \% \\
4,5\end{array}$ & $\begin{array}{l}9,4 \% \\
0,5\end{array}$ & $\begin{array}{c}5,2 \% \\
-6,1\end{array}$ & $\begin{array}{r}4,5 \% \\
-10,9\end{array}$ & $\begin{array}{c}3,4 \% \\
-7,7\end{array}$ & $\begin{array}{c}10,9 \% \\
3,0\end{array}$ & $\begin{array}{c}32,5 \% \\
1,6\end{array}$ & $\begin{array}{c}6,0 \% \\
-1,3\end{array}$ & $\begin{array}{l}0,7 \% \\
-0,2\end{array}$ & $27,0 \%$ \\
\hline Nac./otros ....................... & $\begin{array}{l}10,7 \% \\
-0,8\end{array}$ & $\begin{array}{l}8,8 \% \\
1,6\end{array}$ & $\begin{array}{c}10,3 \% \\
1,9\end{array}$ & $\begin{array}{l}7,7 \% \\
-0,1\end{array}$ & $\begin{array}{l}9,8 \% \\
0,7\end{array}$ & $\begin{array}{c}4,7 \% \\
-3,2\end{array}$ & $\begin{array}{l}6,5 \% \\
-5,3\end{array}$ & $\begin{array}{c}33,4 \% \\
2,3\end{array}$ & $\begin{array}{l}7,4 \% \\
1,7\end{array}$ & $\begin{array}{l}0,7 \% \\
-0,5\end{array}$ & $18,8 \%$ \\
\hline PSOE & $\begin{array}{l}8,5 \% \\
-8,6\end{array}$ & $\begin{array}{l}6,1 \% \\
-6,7\end{array}$ & $\begin{array}{l}8,5 \% \\
-2,3\end{array}$ & $\begin{array}{l}9,0 \% \\
4,4\end{array}$ & $\begin{array}{c}11,3 \% \\
6,5\end{array}$ & $\begin{array}{l}7,7 \% \\
6,0\end{array}$ & $\begin{array}{c}10,1 \% \\
2,0\end{array}$ & $\begin{array}{c}32,3 \% \\
2,0\end{array}$ & $\begin{array}{l}5,5 \% \\
-4,0\end{array}$ & $\begin{array}{l}0,9 \% \\
1,6\end{array}$ & $47,1 \%$ \\
\hline IU & $\begin{array}{c}6,8 \% \\
-4,1\end{array}$ & $\begin{array}{c}10,5 \% \\
2,8\end{array}$ & $\begin{array}{c}10,0 \% \\
0,8\end{array}$ & $\begin{array}{l}9,5 \% \\
1,9\end{array}$ & $\begin{array}{c}14,6 \% \\
5,2\end{array}$ & $\begin{array}{c}11,8 \% \\
6,6\end{array}$ & $\begin{array}{l}8,5 \% \\
-1,0\end{array}$ & $\begin{array}{l}15,4 \% \\
-10,0\end{array}$ & $\begin{array}{c}12,9 \% \\
7,5\end{array}$ & $\begin{array}{l}0,2 \% \\
-2,0\end{array}$ & $7,1 \%$ \\
\hline TOTAL ........................... & $11,2 \%$ & $7,9 \%$ & $9,2 \%$ & $7,8 \%$ & $9,4 \%$ & $6,3 \%$ & $9,6 \%$ & $31,4 \%$ & $6,5 \%$ & $0,7 \%$ & $100,0 \%$ \\
\hline
\end{tabular}

FUENTE: Estudio 1737 CIS. 
Intención de voto (válido) según clase (1991)

(Porcentajes horizontales/residuos ajustados)

\begin{tabular}{|c|c|c|c|c|c|c|c|c|c|c|c|}
\hline & \multicolumn{5}{|c|}{ Clases activas } & \multicolumn{6}{|c|}{ Clases pasivas } \\
\hline & $\begin{array}{c}\text { Vieja cl. } \\
\text { media }\end{array}$ & $\begin{array}{c}\text { Nueva cl. } \\
\text { media }\end{array}$ & $\begin{array}{c}\text { No } \\
\text { manual }\end{array}$ & $\begin{array}{l}\text { Man. } \\
\text { cual. }\end{array}$ & $\begin{array}{c}\text { Man. no } \\
\text { cual. }\end{array}$ & Parado & Jubilado & $\begin{array}{c}\text { Ama } \\
\text { de casa }\end{array}$ & Joven & Resto & Total \\
\hline \multirow[t]{2}{*}{ PP } & $18,5 \%$ & $15,1 \%$ & $13,3 \%$ & $6,2 \%$ & $5,1 \%$ & $5,4 \%$ & $10,1 \%$ & $12,2 \%$ & $11,3 \%$ & $2,8 \%$ & $25,2 \%$ \\
\hline & 5,9 & 0,6 & $-0,3$ & $-4,4$ & $-4,9$ & $-3,2$ & 0,3 & 1,3 & 3,0 & 3,2 & \\
\hline \multirow{2}{*}{ Nac./otros ........................ } & $11,5 \%$ & $20,6 \%$ & $16,5 \%$ & $10,8 \%$ & $5,9 \%$ & $8,8 \%$ & $5,5 \%$ & $9,5 \%$ & $9,9 \%$ & $0,9 \%$ & $25,1 \%$ \\
\hline & $-0,4$ & 5,3 & 2,5 & $-0,1$ & $-4,1$ & 0,4 & $-4,2$ & $-1,3$ & 1,5 & $-1,4$ & \\
\hline \multirow[t]{2}{*}{ PSOE } & $10,1 \%$ & $8,1 \%$ & $10,5 \%$ & $12,4 \%$ & $16,2 \%$ & $10,2 \%$ & $12,8 \%$ & $12,5 \%$ & $6,0 \%$ & $1,2 \%$ & $38,9 \%$ \\
\hline & $-2,3$ & $-7,2$ & $-3,6$ & 1,9 & 8,0 & 2,6 & 4,2 & 2,1 & $-3,6$ & $-0,9$ & \\
\hline \multirow[t]{2}{*}{ IU } & $4,6 \%$ & $20,2 \%$ & $18,6 \%$ & $17,1 \%$ & $10,5 \%$ & $8,2 \%$ & $7,7 \%$ & $5,2 \%$ & $7,3 \%$ & $0,7 \%$ & $10,8 \%$ \\
\hline & $-4,0$ & 3,0 & 2,6 & 3,5 & 0,2 & $-0,2$ & $-1,2$ & $-3,2$ & $-0,7$ & $-1,2$ & \\
\hline TOTAL & $12,0 \%$ & $14,3 \%$ & $13,6 \%$ & $10,9 \%$ & $10,2 \%$ & $8,4 \%$ & $9,7 \%$ & $10,9 \%$ & $8,4 \%$ & $1,5 \%$ & $100,0 \%$ \\
\hline
\end{tabular}

FUENTE: Encuesta ECBC 1991. 
Intención de voto (válido) según clase (1994)

(Porcentajes horizontales/residuos ajustados)

\begin{tabular}{|c|c|c|c|c|c|c|c|c|c|c|c|}
\hline & \multicolumn{5}{|c|}{ Clases activas } & \multicolumn{6}{|c|}{ Clases pasivas } \\
\hline & $\begin{array}{c}\text { Vieja cl. } \\
\text { media }\end{array}$ & $\begin{array}{c}\text { Nueva cl. } \\
\text { media }\end{array}$ & $\begin{array}{c}\text { No } \\
\text { manual }\end{array}$ & $\begin{array}{c}\text { Man. } \\
\text { cual. }\end{array}$ & $\begin{array}{c}\text { Man. no } \\
\text { cual. }\end{array}$ & Parado & Jubilado & $\begin{array}{c}\text { Ama } \\
\text { de casa }\end{array}$ & Joven & Resto & Total \\
\hline 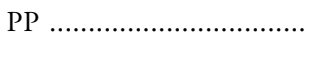 & $\begin{array}{c}14,2 \% \\
7,2\end{array}$ & $\begin{array}{l}9,6 \% \\
-0,1\end{array}$ & $\begin{array}{l}8,9 \% \\
-0,1\end{array}$ & $\begin{array}{c}5,8 \% \\
-3,1\end{array}$ & $\begin{array}{l}5,4 \% \\
-3,7\end{array}$ & $\begin{array}{l}9,8 \% \\
-2,8\end{array}$ & $\begin{array}{l}9,5 \% \\
-1,6\end{array}$ & $\begin{array}{c}26,3 \% \\
2,3\end{array}$ & $\begin{array}{l}8,3 \% \\
1,6\end{array}$ & $\begin{array}{c}2,3 \% \\
-1,4\end{array}$ & $38,5 \%$ \\
\hline Nac./otros ....................... & $\begin{array}{l}9,4 \% \\
-0,1\end{array}$ & $\begin{array}{c}14,0 \% \\
3,6\end{array}$ & $\begin{array}{c}11,7 \% \\
2,5\end{array}$ & $\begin{array}{l}7,0 \% \\
-0,7\end{array}$ & $\begin{array}{l}6,7 \% \\
-0,8\end{array}$ & $\begin{array}{c}12,5 \% \\
0,5\end{array}$ & $\begin{array}{l}8,6 \% \\
-1,6\end{array}$ & $\begin{array}{l}18,4 \% \\
-3,4\end{array}$ & $\begin{array}{l}9,2 \% \\
1,7\end{array}$ & $\begin{array}{l}2,7 \% \\
-0,2\end{array}$ & $17,0 \%$ \\
\hline PSOE $\ldots \ldots \ldots \ldots \ldots \ldots \ldots \ldots \ldots \ldots \ldots \ldots \ldots$ & $\begin{array}{c}5,7 \% \\
-4,4\end{array}$ & $\begin{aligned} & 5,1 \% \\
- & 5,4\end{aligned}$ & $\begin{array}{l}6,1 \% \\
-3,4\end{array}$ & $\begin{array}{c}10,4 \% \\
3,5\end{array}$ & $\begin{array}{l}8,7 \% \\
1,4\end{array}$ & $\begin{array}{l}11,7 \% \\
-0,1\end{array}$ & $\begin{array}{c}15,5 \% \\
5,5\end{array}$ & $\begin{array}{c}29,2 \% \\
4,1\end{array}$ & $\begin{array}{l}3,4 \% \\
-5,2\end{array}$ & $\begin{array}{l}4,2 \% \\
2,9\end{array}$ & $27,6 \%$ \\
\hline IU & $\begin{array}{l}4,7 \% \\
-4,0\end{array}$ & $\begin{array}{c}13,2 \% \\
3,0\end{array}$ & $\begin{array}{c}10,9 \% \\
1,7\end{array}$ & $\begin{array}{l}8,2 \% \\
0,5\end{array}$ & $\begin{array}{c}11,7 \% \\
3,9\end{array}$ & $\begin{array}{c}16,1 \% \\
3,3\end{array}$ & $\begin{array}{l}7,2 \% \\
-2,8\end{array}$ & $\begin{array}{l}16,3 \% \\
-4,5\end{array}$ & $\begin{array}{l}9,8 \% \\
2,4\end{array}$ & $\begin{array}{l}1,9 \% \\
-1,4\end{array}$ & $16,9 \%$ \\
\hline TOTAL $\ldots \ldots \ldots \ldots \ldots \ldots \ldots$ & $9,4 \%$ & $9,7 \%$ & $8,9 \%$ & $7,7 \%$ & $7,6 \%$ & $11,8 \%$ & $10,6 \%$ & $24,1 \%$ & $7,4 \%$ & $2,8 \%$ & $100,0 \%$ \\
\hline
\end{tabular}

FUENTE: Encuesta 2088 CIS. 


\section{A MODO DE CONCLUSION}

He tratado de replantear el debate sobre el papel político de las clases centrando el foco de atención en los nuevos cleavages que emergen con la expansión del Estado de Bienestar. Creo que la evolución electoral del PSOE durante la última década puede explicarse, al menos en parte, como un proceso de intercambio de apoyo electoral por políticas de bienestar, siempre y cuando establezcamos claramente las condiciones y los términos del intercambio. Intento así superar tanto el reduccionismo metodológico característico del análisis de clase tradicional, según el cual la oferta política está determinada por la demanda (léase las paleo-clases), como el reduccionismo simétrico consistente en convertir a las élites políticas en una suerte de deus ex machina que operan en un escenario obediente a su propia racionalidad. Operan, más bien, en un terreno de juego donde los cleavages, las reglas de juego e incluso los efectos de sus propias políticas escapan, con frecuencia, a su control, tal como nos enseña el caso español.

En este caso, la operación redistributiva que se inicia en la segunda mitad de los ochenta resulta clave para entender la evolución electoral del PSOE. En un primer momento, el aumento de la presión fiscal que hizo posible aquella operación podía afectar al apoyo de ciertos sectores de las nuevas clases medias. No cabe argumentar una conexión automática entre lo uno y lo otro, pero era de esperar que si no se suministraba una dosis adecuada de compensaciones materiales o simbólicas, el cleavage no tardaría en cristalizar. En un segundo momento, el gobierno socialista perdió el apoyo de los sindicatos, y en particular de la UGT. Es evidente que el modelo de relación entre partido y sindicato que regía la familia socialista no era el más adecuado después de la crisis de los años setenta, pero las partes no consiguieron establecer un marco institucional que permitiese regular las relaciones mutuas.

La confrontación entre gobierno y sindicatos tuvo resultados imprevistos que siguen condicionando la capacidad de actuación del primero. Así, por ejemplo, el impacto diferencial de las medidas redistributivas adoptadas contribuyó a agudizar un cleavage de carácter generacional y a acelerar el envejecimiento del electorado socialista hasta un grado sin precedentes. Es claro que la política de reducción del déficit y de consiguiente rigor presupuestario exigida por el plan de convergencia europea sería más fácil de gestionar si la población jubilada, muy dependiente del gasto social, no pesara tanto en el electorado socialista, lo que supone una considerable restricción a cualquier decisión estratégica del PSOE. 


\section{REFERENCIAS BIBLIOGRAFICAS}

CAÍnZOS, M. A. (1989): "Clases, intereses y actores sociales: un debate posmarxista", REIS, 46: 81-99.

- (1994): El concepto de estructura de clases: inventario de estrategias constructivas y esbozo de una propuesta, Seminario sobre Desigualdad y Clases Sociales, Fundación Argentaria, octubre (de próxima publicación en Ed. Visor).

Carabaña, J., et al. (1993): Encuesta de Estructura, Conciencia y Biografía de Clase, Documentos de Trabajo, Dpto. de Estadística, Comunidad de Madrid.

COMisión de EXPertos PARA el estudio del Desempleo en España (1991): «El paro: magnitud, causas, remedios», en Bentolila y Toharia (eds.), Estudios de Economía del Trabajo en España. III. El problema del paro, Ministerio de Trabajo y Seguridad Social, pp. 29-71.

CONSEJO ECONÓMICO Y SOCIAL (1995): España 1994. Memoria sobre la situación socioeconómica y laboral.

GunTHER y MONTERO (1994): «Los anclajes del partidismo: un análisis comparado del comportamiento electoral en cuatro democracias del sur de Europa», en P. del Castillo (ed.), Comportamiento politico y electoral, CIS, pp. 467-548.

Esping-Andersen, G. (1990): The Three Worlds of Welfare Capitalism, Princeton University Press.

- (1993a): «Postindustrial Cleavage Structures: A Comparison of Evolving Patterns of Social Stratification in Germany, Sweden, and the United States», en Labor Parties in Postindustrial Societies:, pp. 147-168.

- (1993b): Changing Classes, SAGE.

- (1993c): «Empleo postindustrial y estratificación», en I Simposio sobre Igualdad, vol. V: Estructura social y movilidad, Fundación Argentaria, pp. 35-44.

- (1995): «Politics without Class?», manuscrito inédito.

FELdman, A., et al. (1989): "La estructura social y el apoyo partidista en España», REIS, 47: 7-72.

GARRIDO, L. (1993): «La familia estatal», en GARRIDO y GIL CALVO, Estrategias familiares, Alianza Universidad, pp. 157-180.

- (1995): «Diagnóstico sobre el paro juvenil y políticas para facilitar la entrada al primer trabajo", Estudios de Politicas, n. ${ }^{\circ}$ 16, OIT.

GARRIDO y REQUENA (1995): «El acceso de los jóvenes a la vivienda y al trabajo», Revista Asturiana de Economía, 2: 27-54.

GOLDTHORPE, John (1993): «Sobre la clase de servicio, su formación y su futuro», en Carabaña y De Francisco (eds.), Teorías contemporáneas de las clases sociales, Edit. Pablo Iglesias, pp. 229263.

- (1994): «Modelling the Pattern of Class Voting in British Elections, 1964-92», manuscrito inédito.

González, J. J. (1992a): «El debate postmarxista sobre las clases», Política y Sociedad, 11: $27-48$.

- (1992b): «La construcción empírica de las clases», Política y Sociedad, 11: 99-121.

- (1993): "Clase y apoyo electoral», Sistema, 112: 41-71.

- (1994a): Clases y alineamiento electoral al final del ciclo político, Seminario sobre Desigualdad y Clases Sociales, Fundación Argentaria, octubre (de próxima publicación en Ed. Visor).

- (1994b): «Sobre el declive político de las clases», Economía y Sociedad, 11: 9-24.

- (1995): «Paisaje después de unas primarias», Leviatán, 60: 35-46.

Heath, A., et al. (1991): Understanding Political Change, Pergamon Press.

Herring, C. (1989): Splitting the Middle. Political Alienation, Acquiescence, and Activism Among America's Middle Layers, Praeger.

Hout, M., et al. (1993): "The Persistence of Classes in Post-industrial Societies", International Sociology, 8, 3: 259-277.

Julí̂, S. (1988): La desavenencia. Partido, sindicatos y huelga general, El País-Aguilar. 
Kitschelt, H. (1992): «The Socialist Discourse and Party Strategy in West European Democracies», en Lemke y Marks (eds.), The Crisis of Socialism in Europe, Duke University Press.

- (1993): The Transformation of European Social Democracy, Cambridge University Press.

- (1994): «Los partidos socialistas en la Europa Occidental y el reto de la izquierda libertaria», en Merkel (1994): 121-174.

Leguina, J. (1986): «La evolución del voto 1982-1986. España y Madrid», Sistema, 75: 113125.

LIPSET, S. M., et al. (1991): «Are Classes Dying?», International Sociology, 6, 4: 397-410.

- (1993): "The Declining Significance of Social Class», International Sociology, 8, 3: 293-316.

Marshall, G., et al. (1988): Social Class in Modern Britain, Unwin and Hyman.

Marshall, T. H. (1992 [1950]): Citizenship and Social Class, Pluto Press.

MaraVAll, J. M. ${ }^{a}$ (1992): Los resultados de la democracia, Alianza Editorial.

Merkel, W. (1992): "After the Golden Age», en Lemke y Marks (eds.), The Crisis of Socialism in Europe, Duke University Press.

- (1994): «Teorías e hipótesis acerca del declive de la socialdemocracia», en Merkel (ed.), Entre la modernidad y el postmaterialismo. La socialdemocracia europea a finales del siglo XX. Alianza Universidad, pp. 27-50.

- (1995): ¿Final de la socialdemocracia? Recursos de poder y política de gobierno de los partidos socialdemócratas en Europa Occidental, Edicions Alfons el Magnànim.

Offe, Claus (1988): Partidos politicos y nuevos movimientos sociales, Editorial Sistema.

Paramio, L. (1992): "Los sindicatos y la política en España», en Guerra y Tezanos (eds.), La década del cambio, pp. 521-538.

Pérez-Díaz, Víctor M. (1993): The Return of Civil Society (The Emergence of Democratic Spain), Harvard University Press.

Pérez Royo, J. (1992): «La década moderada», Claves, 26: 24-31.

PRZEWORSKI, Adam (1988): Capitalismo y socialdemocracia, Alianza Universidad.

PrZeWorski y Sprague (1986): Papers Stones. A History of Electoral Socialism, The University of Chicago Press.

Rose y MCAllister (1986): Voters Begin to Choose. From Closed-Class to Open Elections in Britain, SAGE.

- (1990): The Loyalties of Voters. A Lifetime Learning Model, SAGE.

TABOADELA, O. (1993): «Clases sociales y acción colectiva», REIS, 63: 71-98.

TORCAL y CHIBbER (1995): «Elites, cleavages y sistema de partidos en una democracia consolidada: España (1986-1992)», REIS, 69: 7-38.

WRIGHT, Erik Olin (1993): «Reflexionando, una vez más, sobre el concepto de estructura de clases», en Carabaña y De Francisco (eds.), Teorías contemporáneas de las clases sociales, Edit. Pablo Iglesias, pp. 17-126. 


\title{
RESUMEN
}

Este artículo intenta replantear el debate sobre el papel político de las clases prestando atención a los nuevos cleavages que emergen con la expansión del Estado de Bienestar. La evolución electoral de España desde mediados de los años ochenta a mediados de los noventa puede entenderse, al menos en parte, como un proceso de intercambio de apoyo electoral por políticas de bienestar, siempre que dejemos claras las condiciones del mismo. Se intenta así superar tanto el reduccionismo metodológico característico del análisis de clase convencional, según el cual la oferta política está determinada por la demanda (es decir, las paleo-clases), como el reduccionismo simétrico tendente a convertir las élites políticas en una suerte de deus ex machina plenamente capaz de subsumir la demanda política en su propia racionalidad.

\begin{abstract}
This article attempts to readdress the debate on the political role of class paying attention to the new social cleavages linked with Welfare State building process. The Spanish electoral evolution from mid eighties to mid nineties provides us with clear evidence at this point. This process may be understood as an exchange of electoral support for welfare policies, as long as its conditions are specified. The article tries thus to surmount both methodological reductionism bound to conventional class analysis (according to which paleo-classes are decisive in order to shape political supply) and the symmetrical reductionism tented to consider political elites as if they were a kind of deus ex machina wholly able to manage political demand.
\end{abstract}

